\title{
GENDER EFFECTS REGARDING EYEWITNESS IDENTIFICATION PERFORMANCE
}

\section{Original scientific paper}

Primljeno/Recieved: 21.11.2020.

Prihvaćeno/Accepted: 29.11.2020.

\section{Adnan FAZLIĆ Irma DELJKIĆ Ray BULL}

\section{Abstract}

Reason(s) for writing and research problem(s): Previous research has indicated that female eyewitnesses sometimes provide more accurate identifications than male, but there remains a lack of agreement on such a female-superiority effect. The issue of own-gender bias also remains unclear.

Aims of the paper (scientific and/or social): This empirical research aims to further examine the possible existence of gender-related effects in eyewitness identification performance in the rarely studied culture of Bosnia and Herzegovina, and thus to determine implications for eyewitness identification in law enforcement practice there and elsewhere.

Methodology/Design: This experimental study involved 98 undergraduate students of the University of Sarajevo. It included several tasks - participants watched a video recording of a simulated bank robbery, undertook some written tasks, and finally attempted to provide identification of the male perpetrator in a photo lineup.

Research/Paper limitations: The experiment was conducted in laboratory conditions that can be different from real-life situations (usually for ethical reasons). Participants were exclusively undergraduate students. The experiment design included only the identification of a male perpetrator (though most bank robbers are male).

Results/Findings: No effect of gender was found in identification accuracy. An owngender bias was not found.

General conclusion: Gender has no effects on facial recognition, and it is not a useful predictor of accuracy in eyewitnesses. Complete view on gender differences in eyewitness identification may be achieved if gender is considered in combination with other factors such as culture, expectations, age, race, intelligence and face recognition skill and type of crime. In future, it will be useful to explore the relationship between eyewitness identification accuracy and gender stereotypes/roles in countries across which these important factors vary. 
Research/Paper validity: This study's design and analyses correspond to those used in relevant past research.

\section{Key words}

eyewitness identification, gender, eyewitness testimony, criminal investigation science

\section{INTRODUCTION}

Eyewitness identifications and testimonies are among the most controversial and least reliable methods of evidence/proof used in criminal investigations/proceedings (e.g., Swanson et al., 2019). The Innocence Project (2020) data support this in that mistaken eyewitness identifications have been associated with $69 \%$ of the more than 375 wrongful convictions in the United States (to date). Despite the many criticisms and controversies surrounding eyewitness identification/testimony, judges (and jurors) typically overestimate the reliability of eyewitness evidence (Matison Hess et al., 2017) giving it greater credibility than it is usually due.

It is thus important to emphasise that different variables significantly affect the reliability of eyewitness identification. Osterburg and Ward (2014) noted that among the important variables are: a) procedures during lineups; b) witness stress or pressure; c) racial bias; d) lighting during crime; and e) time between the criminal act and identification. Wells (1978) innovatively classified these variables into two groups: system variables and estimator variables. System variables are under the direct control of the criminal justice system (such as interrogation/interview technique, question structure, lineup structure, lineup instruction). In contrast, estimator variables (characteristics of the criminal event, of the defendant or the eyewitness) cannot be controlled in actual criminal cases and thus they have limited potential for improving eyewitness identification/testimony procedures.

One readily available estimator variable is the gender of the witness, and Memon et al. (2003) noted that in addition it is a stable witness characteristic. Thus, in criminal investigations/proceedings, this variable is available for possible utilisation by investigators, judges and so on. Indeed, Stern (1903-1904) innovatively found that females were less accurate witnesses (Butts et al., 1995). In contrast, in the 1970s and 1980s research that again explored gender differences (e.g., Clifford \& Bull, 1978; Shapiro \& Penrod, 1986; Loftus et al., 1987) found that females seemed better at recognising human faces they had seen before. Although such authors warned that their findings were from laboratory studies, these findings might have been taken into 
account in police and judicial practice. However, Maccoby and Jacklin (1974) claimed that stable gender-related differences do not exist in most laboratory conditions. Nevertheless, some of the research that followed (e.g., Horgan et al., 2004; Rehnman \& Herlitz, 2007; Areh, 2011; Vredeveldt et al. 2015; Longstaff \& Belz, 2020) also found gender effects in whole or in part.

However, it is useful to highlight some of the divergences in the findings of these studies. For example, Clifford and Bull (1978) concluded that whereas females were better in recognising faces in non-emotive situations, males outperformed females in stressful situations. Furthermore, Shapiro and Penrod (1986) in their meta-analysis, claimed that although females are slightly better regarding correct eyewitness performance, they also more often provide mistaken identifications. Loftus et al. (1987) presented similar results, noting that females are better regarding verbal memory but that males are better regarding spatial memory. To complicate matters further, Deblieck \& Zaidel (2003) found that females were better at remembering attractive faces both male and female), but that males were better at remembering unattractive faces (of both genders). However, other researchers have found female superiority regarding face recognition regardless of target gender, especially when asked to describe others' appearance (Horgan et al., 2004, Areh, 2011; Vredeveldt et al., 2015). Even more complicating is that some authors have found that female witnesses perform better only when recognising female faces (e.g., Lewin \& Herlitz, 2002; Rehnman \& Herlitz, 2007; Lovén et al., 2011; Westerberg et al., 2020) or that both males and females exhibit an own-gender bias (Wright \& Sladden, 2003; Mukudi \& Hills, 2019). Recent studies have also provided some new insights/complications, such as that female witnesses have better memory for clothes and personal artefacts (Horgan et al., 2017) or for details related to persons, whereas males are more accurate for details from the environment (Longstaff \& Belz, 2020).

The authors who have found a female superiority have provided different explanations. Shapiro and Penrod (1986) hypothesised that reasons are reflected in a more apparent desire of females to be effective and to comply with a researcher. Other explanations imply that females retain their attention longer to the stranger than do males due to caution because they want to assess further potential danger (Areh, 2011; Longstaff \& Belz, 2019). Loftus et al. (1987) contended that females have historically different social roles that contribute to the development of different interests between females and males. Similarly, some authors (e.g., Jobson \& Watson, 1984) considered that women are more oriented toward other people in interpersonal relationships (think more about other people, show more empathy, pay more attention to nonverbal cues) than are men. On a related note, greater interest in other people and/or a more pronounced concern regarding physical appearance may 
motivate females to better remember details of other people (Horgan et al., 2004, 2017). Such research has begun to highlight that 'gender' does not exist in a vacuum but is to some extent a reflection of contexts and cultures.

Even though some of the above studies have found gender differences and offered various explanations for this, other researchers did not obtain any such findings (e.g., Butts et al., 1995; Wells \& Olson, 2003; Willmott \& Sherretts, 2016). Therefore, it is evident that there is considerable inconsistency in previous research. This could partly be because this topic is not well-enough studied by psychologists who themselves have sensitivity and expertise in gender issues (Walker et al., 2020) and also possibly because of relevant cultural/national variations in gender roles/socialisation.

The inconsistencies in the above findings, as well as the lack of such research in the culture of Bosnia and Herzegovina (a country that rarely has been part of the body of relevant research), served as inspiration for the present study.

\section{METHODOLOGY}

Participants. The sample consisted of undergraduate students from the University of Sarajevo - UNSA ( $N=98 ; 55$ - male, 43 - female; mean age $=18.9$ years, $S D=.634)$ who participated individually but in groups of up to ten (for course credit).

Procedure: The first task involved watching a video recording of a simulated bank robbery lasting 44 seconds. Before watching the video recording, the students were informed that they would participate in a study of memory and perception, and they signed informed consent. Also, at the beginning of the experiment, the students were given this instruction: "This experiment consists of several tasks. First, please pay close attention to the following video". After this, because the video recording was emotionally neutral, it was explained to the participants that the video recording depicts a simulated bank robbery. Following this explanation, they had five minutes in which to undertake a distractor written task that involved describing the perpetrator or listing of capital cities of the European countries. Subsequently, they had another 20 minutes to perform a distractor crossword puzzle task. Immediately after this, participants attempted to identify the perpetrator of the robbery from a set of eight male facial photographs (that did include the perpetrator, though the option to indicate his non-presence was made available). 


\section{RESULTS}

Table 1 shows that (i) $56.4 \%(\mathrm{~N}=31)$ of male participants accurately identified the perpetrator and $43.6 \%(N=24)$ provided a misidentification, whereas for females accurate identification was provided by $44.2 \%(\mathrm{~N}=19)$ and mistaken identification by $55.8 \%(N=24)$. A chi-square test $\left(\chi^{2}=1,43, p>0,05\right)$ indicates that gender was not significantly associated with identification accuracy.

Table 1. Gender and accurate performance

Gender

\begin{tabular}{lcc} 
& Male (\%) & Female (\%) \\
\cline { 2 - 3 } Accurate Identification & $31(56,4)$ & $19(44,2)$ \\
Mistaken Identification & $24(43,6)$ & $24(55,8)$
\end{tabular}

Mistaken identifications were divided into the two categories of a) false identification and $\mathrm{b}$ ) rejected identification. Table 2 . shows that of the male participants $27.3 \%$ ( $N=$ 15) provided a false identification and $16.4 \%(\mathrm{~N}=9)$ provided a rejected identification. For female participants the corresponding figures are $32.6 \%(N=14)$ false identifications and $23.3 \%(\mathrm{~N}=10)$ rejected identifications. A chi-square test found no significant gender differences $\left(\chi^{2}=1,521, p>0,05\right)$.

Table 2. Gender and incorrect identification

Gender

\begin{tabular}{ccc} 
& Male (\%) & Female (\%) \\
\cline { 2 - 3 } & $15(27,3)$ & $14(32,6)$ \\
Ralse Identification & $9(16,4)$ & $10(23,3)$
\end{tabular}

\section{DISCUSSION}

It is evident that the results of the current study do not support the notion that females provide more accurate identifications nor that males provide more rejected identifications. The findings of the current study corroborate the research of Butts et al. (1995), of Willmott and Sherretts (2016) and of Maccoby \& Jacklin (1974). The 
present findings in a new to such research country underpin the need for caution regarding sweeping generalisations/conclusions regarding gender and eyewitness identification performance (Clifford \& Bull, 1979).

One of the possible explanations for why the present study did not find a femalesuperiority effect could be that participants watched an emotionally neutral video recording. Videos of violent crimes have been used in several studies that have found a female-superiority effect (e.g., Lindholm \& Christianson, 1998; Areh, 2011). However, if we consider the findings noted by Clifford and Bull (1979), it also could be expected that emotionally neutral video recording in our study will cause a female-superiority effect. Given that a female-superiority effect was not observed, it is reasonable to assume that the nature of a video recording does not affect gender differences in eyewitness identification.

Another explanation may involve the lack of overall life experience in the current study's participants, as well as the lack of experience with the eyewitness identification lineups. The average age of the participants was 18.9 years, and none of the participants had previously participated in a similar When it comes to the impacts of this study on a law enforcement practice, it must be observed that the present experiment was conducted in the laboratory conditions. These conditions can be considered as a limitation of this study because of real-life eyewitnesses observe crimes in different environments and conditions. (Willmott \& Sherretts, 2016).

The present study did not correspond with research that has found an own-gender bias in male participants (Wright \& Sladden, 2003; Mukudi \& Hills, 2019). The absence of a female perpetrator can also be explained as a limitation of the present study, considering that some of the previous studies (e.g., Lewin \& Herlitz, 2002; Lovén et al., 2011; Westerberg et al., 2020) have shown own-gender bias in female participants. Nevertheless, a significant limitation of this study also is the lack of "target absent" set of photos, because it was not possible to determine potential gender differences in "target present" and "target absent" experimental groups.

The results indicate that the eyewitness gender may well not be a useful predictor of accurate identification. However, it should be noted that in combination with other factors such as culture, expectations, age, race, intelligence, crime type, and face recognition skill, gender may have an influence on eyewitness identification. Future research could pay attention to the combined influence of such factors. 
Regarding this, it is essential to note that cultural factors can have a strong influence on the skills and interests of males and females (Burton et al., 2019). Some previous studies (e.g., Brown \& Josephs, 1999) have shown that social stereotypes about gender differences in their abilities can influence task performance of males and females, especially in situations when they are told that their performance will indicate how good or weak are they in some ability or skill. This type of instruction can lead to relatively low performance and relative lack of confidence in women. On the other side, it does not affect men (Brown \& Josephs, 1999). Furthermore, cultural stereotypes regarding gender roles promote and maintain the notion that women are relatively communal and men are relatively agentic (Rivera \& Veysey, 2016), which is especially visible in patriarchal societies where gender roles are very significant.

Additionally, Rivera and Veysey (2016) suggest that both men and women express a tendency to behave in a manner consistent with gender stereotypes, or consistent with expectations defined by society. If society implies masculine environment in which interpersonal interactions take place, women are at particular risk of low selfconfidence (Burnett et al., 1995). In this regard, it should be considered that men and women have different sources of self-esteem and self-confidence (Josephs et al., 1992).

Considering that the participants in our study were mainly students of the Faculty of Criminalistics, Criminology and Security Studies of the University of Sarajevo, and that they were aware that their final task was to identify crime perpetrator, the results should also be considered through a prism of the stereotype that law enforcement is a male-dominated profession (Davis, 2005). These factors are important because gender stereotypes and negative attitudes about women in law enforcement are present in Bosnia and Herzegovina (e.g., Muftić \& Carter Collins, 2013; Gačanica, 2019), so this masculine-related environment could well have influenced the findings. Notwithstanding that the participants were not provided with explicit information about gender and task performance, or with gender cues in the labelling of law enforcement profession (Colley et al., 2002), previous experiences and insights of female participants could negatively affect their self-confidence and identification performance. On the other hand, the instructions given to the participants at the beginning of the experiment could give the female participant the impression that it was a competitive test of memory and perception. The sense of competitiveness could create a sense of anxiety and negatively affect female task performance. These findings can also be considered in terms of the fact that self-confidence and identification accuracy are strongly related (Wixted \& Wells, 2017). 
A masculine environment is significantly present in Bosnia and Herzegovina, where the stereotypes relating to gender roles imply that women are primary "child care providers" and "housekeepers" and that men are primary "breadwinners" (Halilović \& Huhtanen, 2014). It is almost equally expressed in urban and rural areas (Hughson, 2014). In this kind of environment, society's expectations of women and men are different, while deviations from gender roles are not encouraged (Somun-Krupalija, 2011). That our study did not confirm a female-superiority effect should be considered in terms of cultural differences between Bosnia and Herzegovina and other countries that have different attitudes towards gender roles.

\section{CONCLUSION}

This study provides an innovative account of possible gender effects regarding eyewitness identification performance. A more comprehensive view on gender differences in eyewitness identification may be achieved if gender is considered in combination with other factors such as culture, expectations, age, race, intelligence, face recognition skill and type of crime. The present study indicates the need for a more comprehensive study in Bosnia and Herzegovina, that would consist a detailed consideration of heterogeneous and larger sample of participants, the use of male and female perpetrator, as well as target-present and target-absent photosets.

\section{REFERENCES}

1. Areh, I. (2011). Gender-Related Differences in Eyewitness Testimony. Personality and Individual Differences, 50(2011), 559-563.

2. Brown, R. P., \& Josephs, R. A. (1999). A Burden of Proof: Stereotype Relevance and Gender Differences in Math Performance. Journal of Personality and Social Psychology, 76(2), 246-257.

3. Burnet, J. W., Anderson, W. P., \& Heppner, P. P. (1995). Gender Roles and SelfEsteem: A Consideration of Environmental Factors. Journal of Counseling \& Development, 73(3), 323-326.

4. Burton, L., Drew, W., \& Kowalski, R. (2019). Psychology, Fifth Australian and New Zealand Edition. Wiley.

5. Butts, S. J., Mixon, K. D., Malekar, M. S., \& Bringmann, W. G. (1995). Gender Differences in Eyewitness Testimony. Perceptual and Motor Skills, 80, 59-63.

6. Clifford, B. R. \& Bull, R. (1978). The Psychology of Person Identification. Routledge \& Kegan Paul.

7. Colley, A., Ball, J., Kirby, N., Harvey, R., \& Vingelen, I. (2002). Gender-Linked Differences in Everyday Memory Performance. Effort Makes Difference. Sex Roles, 47, 577-582. 
8. Davis, T. A. (2005). Gender Inequality in Law Enforcement and Males' Attitudes and Perceptions Toward Women Working in Law Enforcement. The University of Texas at Arlington.

9. Deblieck, C., \& Zaidel, D. (2003). Hemi-field memory for attractiveness. International Journal of Neuroscience, 113, 931- 941.

10. Gačanica, L. (2019). Gender-Based Discrimination and Labour in Bosnia and Herzegovina. Helsinki Citizens' Assembly Banja Luka.

11. Halilović, M., \& Huhtanen, H. (2014). Gender and the Judiciary: The Implication of Gender within the Judiciary of Bosnia and Herzegovina, Research Report. DCAF.

12. Horgan, T. G., McGrath, M. P, Bastien, C., \& Wegman, P. (2017). Gender and Appearance Accuracy: Women's Advantage over Men is Restricted to Dress Items. The Journal of Social Psychology, DOI: 10.1080/00224545.2017.1282848.

13. Horgan, T. G., Schmid Mast, M., Hall, J. A., \& Carter, J. D. (2004). Gender Differences in Memory for the Appearance of Others. Personality and Social Psychology Bulletin, 30(2), 185-196.

14. Hughson, M. (2014). Gender Country Profile for Bosnia and Herzegovina, final report. European Commission.

15. Innocence Project (2020). Eyewitness Identification Reform. Available on: https://innocenceproject.org/eyewitness-identification-reform/, approached 13.11.2020.

16. Jobson, S. \& Watson, J. S. (1984). Sex and age differences in choice behaviour: The object-person dimension. Perception, 13, 719-724.

17. Josephs, R. A., Rose Markus, H., \& Tafarodi, R. W. (1992). Gender and Self-Esteem. Journal of Personality and Social Psychology, 63(3), 391-402.

18. Lewin, C. \& Herlitz, A. (2002). Sex Differences in Face Recognition - Women's Faces Make the Difference. Brain and Cognition, 50 (2002), 121-128.

19. Lindholm, T. \& Christianson, S. Å. (1998). Gender Effects in Eyewitness Accounts of a Violent Crime. Psychology, Crime \& Law, 4(4), 323-339.

20. Loftus, E. F., Banaji, M. R., Schooler, J. W., \& Foster, R. (1987). Who Remembers What?: Gender Differences in Memory. Michigan Quarterly Review, 26, 64-85.

21. Longstaff, M. G. \& Belz, G. K. (2020). Sex Differences in Eyewitness Memory: Females are More Accurate than Males for Details Related to People and Less Accurate for Details Surrounding Them, and Feel More Anxious and Threatened in a Neutral but Potentially Threatening Context. Personality and Individual Differences, 164 (2020) 110093.

22. Lovén, J., Herlitz, A., \& Rehnman, J. (2011). Women's Own-Gender Bias in Face Recognition Memory: The Role of Attention at Encoding. Experimental Psychology, 58(4), 333-340.

23. Maccoby, E. E. \& Jacklin, C. N. (1974). The Psychology of Sex Differences. Stanford University Press. 
24. Matison Hess, K., Hess Orthmann, C., \& Cho, H. L. (2017). Criminal Investigation, Eleventh Edition. Cengage Learning.

25. Memon, A., Vrij, A. \& Bull, R. (2003). Psychology and Law: Truthfulness, Accuracy and Credibility, Second Edition. Wiley.

26. Muftić, L. R., \& Carter Collins, S. (2014). Gender Attitudes and the Police in Bosnia and Herzegovina: Male Officers' Attitudes Regarding Their Female Counterparts. Police Practice and Research: An International Journal. 15(5), 389-403.

27. Mukudi, P. B. L. \& Hills, P. J. (2019). The Combined Influence of the Own-Age, Gender, and -Ethnicity Biases on Face Recognition. Acta Psychologica, 194 (2019), 1-6.

28. Osterburg, J. W. \& Ward, R. H. (2014). Criminal Investigation: A Method for Reconstructing the Past, Seventh Edition. Anderson Publishing.

29. Rehnman, J. \& Herlitz, A. (2007). Women Remember More Faces Than Man Do. Acta Psychologica, 124(3), 344-355.

30. Rivera, L. M., \& Veysey, B. M. (2016). Criminal Justice System Involvement and Gender Stereotypes: Consequences and Implications for Women's Implicit and Explicit Criminal Identities. Albany Law Review, 78(3), 101-120.

31. Shapiro, P. N. \& Penrod, S. (1986). Meta-Analysis of Facial Identification Studies. Psychological Bulletin, 100, 2, 139-156.

32. Somun-Krupalija, L. (2011). Gender and Employment in Bosnia and HerzegovinaA Country study, working paper. Bureau of Gender Equality/International Labour Office.

33. Swanson, C. M. R., Chamelin, N. C., Territo, L., \& Taylor, R. W. (2019). Criminal Investigation, Twelfth Edition. McGraw-Hill Education.

34. Vredeveldt, A., Knol, J. W., \& Van Koppen, P.J. (2015). Observing Offenders: Incident Reports by Surveillance Detectives, Uniformed Police and Civilians. Legal and Criminological Psychology, 20, 1-14. DOI: 10.1111/Icrp.12087.

35. Walker, L. E., Shapiro, D., \& Akl, S. (2020). Introduction to Forensic Psychology: Clinical and Social Psychological Perspectives, Second Edition. Springer.

36. Wells, G. L. (1978). Applied Eyewitness-Testimony Research: System Variables and Estimator Variables. Journal of Personality and Social Psychology, 36, 15461557.

37. Wells, G. L. \& Olson, E. A. (2003). Eyewitness Testimony. Annual Review of Psychology, 54, 277-295.

38. Westerberg, C. E., Wofford, N., Menssor, S., Reininger, B. P., \& Deason, R. G. (2020). Face Category Differentially Influences Face Memories After Delay. Journal of Cognitive Psychology, DOI: 10.1080/20445911.2020.1809432.

39. Willmott, D. \& Sherretts, N. (2016). Individual Differences in Eyewitness Identification Accuracy Between Sequential and Simultaneous Line-ups: 
Consequences for Police Practice and Jury Decisions. Current Issues in Personality Psychology, 4(4), 2016, DOI: 10.5114/cipp.2016.62701.

40. Wixted, J. T., \& Wells, G. L. (2017). The Relationship Between Eyewitness Confidence and Identification Accuracy: A New Sythesis. Psychological Science in the Public Interest, 18(1), 10-65.

41. Wright, D. B. \& Sladden, B. (2003). An Own Gender Bias and the Importance of Hair in Face Recognition. Acta Psychologica, 114 (2003), 101-114.

\footnotetext{
About the authors

Adnan Fazlić, PhD, senior teaching assistant, Faculty of Criminalistics, Criminology and Security Studies, University of Sarajevo.

E-mail: afazlic@fkn.unsa.ba

Irma Deljkić, PhD, full professor, Faculty of Criminalistics, Criminology and Security Studies, University of Sarajevo:

E-mail: ideljkic@fkn.unsa.ba.

Ray Bull, PhD, emeritus professor, Department of Law and Social Sciences, University of Derby.

E-mail: rhb10@leicester.ac.uk.
} 